\title{
Efficient carbon recycling at the Central-Northern Lesser Antilles Arc: Implications to deep carbon recycling in global subduction zones
}

\author{
KAN LI ${ }^{1}$, LONG LI ${ }^{1}$, CYRIL AUBAUD ${ }^{2}$, KARLIS \\ MUEHLENBACHS ${ }^{1}$
}

${ }^{1}$ Department of Earth and Atmospheric Sciences, University of Alberta, Canada, T6G 2E3

${ }^{2}$ Laboratoire de Geochimie des Isotopes Stables, Institut de Physique du Globe, Université de Paris

Carbon recycling efficiency of arc (CREA), defined as the fraction of slab carbon in the subducted sediments and altered oceanic crust (AOC) that is released through arc volcanism, is an important parameter to assess the recycling of slab carbon into Earth's deep interior. Previous studies have shown that slab carbon being recycled through arcs is highly variable on a global scale, e.g., the recycled carbon released in the Central American (CA) arc only accounts for $12-29 \%$ of the carbon in the carbonate-rich subducting sediments [1], but the recycled carbon in the Sunda arc is higher than the subducting sedimentary carbon and requires the carbon in oceanic crust to account for [2]. However, due to the loose constraints on carbon budget in AOC, the CREA value of any individual subduction zone has not been obtained yet. Here, we assessed the carbon recycling efficiency in the Central-Northern Lesser Antilles (C-N LA) arc by comparing the carbon input flux (estimated from data of the subducting slab recovered by DSDP Site 543) with carbon output flux (estimated based on data of gas from major volcanoes). We found an extremely efficient carbon recycling case, with the CREA value reaching $100^{ \pm 27} \%$. Nearly complete slab carbon release at sub-arc depth indicates minimal carbon loss within the forearc region and little carbon subduction into the deep mantle in the C-N LA subduction zone. Compared with the carbon recycling case of the other subduction zones (e.g., CA and Sunda), our results highlight strongly variable CREA on a global scale, which needs to be considered in the modeling of global deep carbon cycle.

[1] De Leeuw, G. (2007) Earth Planet. Sci. Lett. 258, 132146. [2] House, B.M. (2019) Geology. 47 (5), 483-486. 